\title{
Managing Hypertension by Polyphenols
}

Authors

Affiliations
Salvador Fernández-Arroyo ${ }^{1}$, Jordi Camps ${ }^{1}$, Javier A. Menendez ${ }^{2}$, Jorge Joven ${ }^{1}$

${ }^{1}$ Unitat de Recerca Biomèdica, Hospital Universitari Sant Joan, Institut d'Investigació Sanitària Pere Virgili, Universitat Rovira i Virgili, Campus of International excellence Southern Catalonia, Reus, Spain

${ }^{2}$ Metabolism and Cancer Group, Translational Research Laboratory, Catalan Institute of Oncology-Girona, Molecular Oncology, Girona Biomedical Research Institute, Girona, Spain

\author{
Key words \\ - Hibiscus sabdariffa \\ - Malvaceae \\ - botanical extracts \\ - cardiovascular risk \\ - hypertension \\ - oxidation \\ - metabolism \\ polyphenols
}

received July 29,2014

revised January 15, 2015

accepted January 15, 2015

\section{Bibliography}

DOI http://dx.doi.org/

10.1055/s-0034-1396310

Published online February 25, 2015

Planta Med 2015; 81: 624-629

(c) Georg Thieme Verlag KC

Stuttgart · New York .

ISSN 0032-0943

\section{Correspondence}

\section{Jorge Joven}

Unitat de Recerca Biomèdica Hospital Universitari Sant Joan Institut d'Investigació Sanitària Pere Virgili

Universitat Rovira i Virgili

Campus of International

Excellence, Southern Catalonia

Carrer Sant Llorenç 21

43201, Reus

Spain

Phone: + 34977310300

ext. 55409

jorge.joven@urv.cat

\section{Abstract \\ $\nabla$}

Some polyphenols, obtained from plants of broad use, induce a favorable endothelial response in hypertension and beneficial effects in the management of other metabolic cardiovascular risks. Previous studies in our laboratories using the calyces of Hibiscus sabdariffa as a source of polyphenols show that significant effects on hypertension are noticeable in humans only when provided in high amounts. Available data are suggestive in animal models and ex vivo experiments, but data in humans are difficult to acquire. Additionally, and despite the low bioavailability of polyphenols, intervention studies provide evidence for the protective effects of secondary plant metabolites. Assumptions on public health benefits are limited by the lack of scientific knowledge, robust data derived from large randomized clinical trials, and an accurate assessment of the bioactive compo-

\section{Hypertension: Multiple Guidelines Reflecting an Unsolved Issue \\ $\nabla$}

Hypertension is the most important risk factor in the development of cardiovascular diseases (CV) but its pathophysiology remains incompletely understood. Hypertension is clinically defined as systolic blood pressure (SBP) $\geq 140 \mathrm{mmHg}$ and/or diastolic blood pressure (DBP) $\geq 90 \mathrm{mmHg}$. Taking an antihypertensive medication is also used as an alternative description. The publication of multiple hypertension guidelines reflects a continuous debate and an unsolved issue. The upper levels of normal ranges of blood pressure (BP) are based on, firstly, epidemiological findings relating $\mathrm{BP}$ levels to risks for adverse outcomes and, secondly, clinical trials demonstrating a reduced risk of adverse outcomes with antihypertensive therapies. Recently, members appointed to the Eighth Joint National Committee, independent of any spon- nents provided by common foodstuff. Because it is likely that clinical effects are the result of multiple interactions among different polyphenols rather than the isolated action of unique compounds, to provide polyphenol-rich botanical extracts as dietary supplements is a suggestive option. Unfortunately, the lack of patent perspectives for the pharmaceutical industries and the high cost of production and release for alimentary industries will hamper the performance of the necessary clinical trials. Here we briefly discuss whether and how such limitations may complicate the extensive use of plant-derived products in the management of hypertension and which steps are the necessary to deal with the predictable complexity in a possible clinical practice.

Supporting information available online at http://www.thieme.connect.de/products

soring agency, have updated the management of high BP [1]. The recommendation to change the treatment goal for individuals aged 60 years or older with hypertension has raised some concerns in scientific associations with an interest in hypertension. The new guideline sets goals for SBP and diastolic DBP at less than $150 / 90 \mathrm{mmHg}$ (previously $140 / 90 \mathrm{mmHg}$ ) in these patients. The diastolic goal of less than $90 \mathrm{mmHg}$ is also recommended for hypertensive persons 30 through 59 years of age. They did not find evidence in hypertensive persons younger than 60 years for a systolic goal, or in those younger than 30 years for a diastolic goal, and recommend a BP of less than $140 / 90 \mathrm{mmHg}$ for those groups. It is generally accepted that among patients with hypertension, those with an elevated SBP carry the highest risk for cardiovascular events but once the SBP is below $140 \mathrm{mmHg}$, the risk of incident CV does not change [2]. Relevant to our discussion, the diag- 
nosis of prehypertension in a child or adolescent represents an increased risk for early-onset CV disease, and it is apparently related to being overweight, insulin resistance, and metabolic syndrome [3]. Also, the prevalence of resistant hypertension, high BP that remains above the accepted goals despite concomitant use of three or more antihypertensive agents, is increasing and apparently related to older age and metabolic disturbances [4].

Underdiagnosis of hypertension is apparently high. There are no reliable data, but substantial reductions in the number of unaware and/or untreated hypertensive patients should be a major clinical goal. Despite an increase in the number and tolerability of antihypertensive medications, undertreatment is extraordinarily high, a situation that is also observed with respect to other cardiovascular risk factors. In clinical trials, the control rates in hypertensive patients is $60-70 \%$ [5], but in the "real world" it appears to be $<30 \%$ [6]. Multiple factors have been cited for the low BP control (e.g., low compliance or limited access to medication), but the impact of therapeutic inertia seems to be high and an impediment to achieve satisfactory control rates [7]. Therapeutic inertia is defined as the failure to increase therapy when treatment goals are unmet, and in a context of multiple guidelines, it is likely to increase. We propose a pragmatic alternative or complementary approach based on the increase of the daily intake of polyphenols to decrease the failure to control $\geq 70 \%$ of treated patients.

\section{Hibiscus sabdariffa and Hypertension: The Importance of the Preparation and the Assessment of Phytochemical Composition $\nabla$}

"I've heard the hibiscus tea is helpful for high blood pressure. Is that true?" [8]. Despite a possible disagreement, our data suggest a negative answer [9]. Simply, the amount of ingested bioactive compounds is too low in current herbal teas. Frequently, herbal tea manufacturers do not provide information on the source and origin of Hibiscus sabdariffa L. (HS), the mode of preparation, phytochemical composition of the plant used in their products, and the resulting dose in the hibiscus beverage. Of note, data on the amount of imported plants are unreliable but apparently England, Germany, and the USA are the most prominent markets in Western societies. In these countries, HS is combined with many other ingredients used for the manufacturing of herbal teas including other natural products (i.e., mainly by-products of lemon, apple, or orange) and commercialized as "red or sour teas".

Our findings in humans, animal models, and in vitro experiments strongly suggest that polyphenols have a beneficial role in the prevention and therapy of hypertension, but the phytochemical composition of the HS extract is important information needed to provide the required amount (our data indicate that this should be approximately $70 \mathrm{mg} / \mathrm{kg}$, p. o.) [9]. The description of the raw material, harvested in Senegal, and the extracts we used in our experiments may be found as Supporting Information. The genus Hibiscus (Malvaceae) includes more than 300 species of annual or perennial herbs, shrubs, or trees. There are two main varieties of HS, altissima and sabdariffa, with different races, bhagalpuriensi, intermedius, albus, and ruber. The information provided in this report to highlight the beneficial effect of HS in hypertension has been obtained with the calyces of HS race ruber, which is an annual, erect, bushy, herbaceous subshrub. The calyx is red, consisting of five large sepals and bracteoles around the base that enclose a velvety capsule, which turns brown and splits open when mature and dry [10]. The calyx aqueous extract is acid, resembles the cranberry in flavor, and has a potent in vitro antioxidant effect. Of note, in the quest for pharmacological actions, it is important to recognize that the polyphenol content of the extract is likely responsible for the effect, but also that this is a poorly defined term, which may include other possible bioactive compounds. There are significant amounts of saccharides in HS extracts (approximately 15\%) including arabinose, galactose, and glucose. The mucilage content is approximately $20 \%$ and predominantly composed by anhydrouronic acid. This "complete" aqueous extract is apparently safe, and in mice the $\mathrm{LD}_{50}$ is consistently $>2500 \mathrm{mg} / \mathrm{kg}$ body weight (unpublished data). It is relatively easy but substantially more expensive to prepare pure polyphenolic extracts (see Supporting Information), but the toxicity has not been tested. Additionally, no therapeutically relevant interaction potential has been reported, and we did not find significant effects on CYP450 activity in mice cotreated with acetaminophen (unpublished data). The mode of harvesting, conservation, and preparation necessarily alters this information and requires standardization in the preparation of each batch [11] This is a considerable obstacle for the correct assessment of clinical effects. Further, the "quality" of HS (measured as the amount of polyphenols per gram of dried calyces) strongly depends on local agricultural methods and the geographic origin. To our knowledge, different preparations of HS are available, at least, from China, Thailand, Sudan, Mexico, Egypt, Senegal, Tanzania, Mali, and Jamaica, countries in which HS has been traditionally used for food and medicine.

\section{Polyphenols and Hypertension: \\ Anecdotes Coalesce into Data and Probably Useful Knowledge \\ $\nabla$}

In clinical trials and preclinical experiments, it is common to find disparate results regarding the size of the effect on BP attributed to polyphenols, but results seem to indicate the concurrence of multiple mechanisms. In animals, most data suggest a diuretic effect, but HS extracts may also improve metabolism, and the antiinflammatory and antioxidant activities are prominent [9-16]. Moreover, HS extracts significantly reduced BP in spontaneously hypertensive rats $(125$ or $60 \mathrm{mg} / \mathrm{kg}$ in a single dose or daily for one week) [9]. In humans with metabolic syndrome, the effects are similar. In patients with mild to moderate hypertension, a diuretic effect was observed during treatment with an HS extract characterized as containing $9.6 \mathrm{mg}$ of anthocyanins [17]. However, using different compositions, clinical studies performed in Thailand failed in finding a diuretic effect $[18,19]$. Because composition and the amount of polyphenols provided differ in all published studies, or the data are not well characterized, the effectiveness of HS for the treatment of hypertension and its putative diuretic effect are apparently inconclusive when the criteria to establish the quality of randomized clinical trials (RCTs) are exclusively based on randomization and blinding [20,21]. However, clinical observations in patients with concomitant metabolic disturbances indicate uniform and constant beneficial effects of polyphenols in their BP. The fact that a placebo effect is apparently negligible using $24 \mathrm{~h}$ ambulatory blood pressure oscillometric monitoring is also clinically important [22]. Additionally, adherence seems to be higher than that obtained with marketed drugs, and this effect may be important to reduce the factors affecting the low control rates in hypertensive patients. It has also been 
proposed that criteria for RCTs could be expanded in the assessment of evidences related to the medicinal use of botanicals [23, 24]. Consequently, when RCTs are reviewed in the context of the phytochemical, ethnomedical, pharmacological, and toxicological information, the conclusion is that extracts of HS are "promising" as a treatment for hypertension [25]. The establishment of the actual relevance for public health benefits requires high-quality human studies, and recent reports include a substantial number of the CONSORT items relevant to all RCTs. Robust conclusions face a number of limitations derived from the diverse clinical population (i.e., included healthy participants as well as those with metabolic syndrome, hyperlipidemia, hypertension, or type 2 diabetes mellitus), different doses of HS, as well as differing preparation of the extracts and frequency of administration. Other limitations that should be carefully assessed relate to the information on phytochemical composition and the duration of treatment; most lasted from 15 days to 2 months [9,17,26-31]. Hence, comparisons are difficult to sustain.

We therefore believe that the beneficial effects of HS on hypertension are not a folkloric claim but will remain anecdotic until further investments in financial and research effort clarify these important questions. This may be apparently profitable because, when taking into account the available data, it seems to coalesce into a considerable body of reliable knowledge. Importantly, plant-derived compounds may also increase the compliance in the treatment of hypertension. This is an important issue because it is a common observation that physicians do not correctly prescribe first-line drugs for their patients with high BP and when prescribed, these are not taken by the patients [32]. As mentioned above, the consequence is that hypertension is generally undertreated [33-35]. Dietary supplements may provide an additional tool to be successful in the effort to reverse this situation. In addition to evidences provided by HS, this may also be applied to the extract of leaves from Camellia sinensis or "green tea", which is one of the most commonly consumed beverages worldwide and contains different phytochemicals including phenols and catechins [36]. In this case, probably due to evident economic profits, the manufacturers of green tea have financed a substantial number of RCTs to prove effects on hypertension. High doses have not been tested. Value for evidence-based medicine should not be granted, but it should be remembered that methodological flaws are common in published medical research (>20\%) and that RCTs have as many limitations as non-RCTs [37]. Case-control studies and epidemiological studies strongly suggest that green tea intake is cardioprotective, but meta-analyses are not conclusive. One study [38] indicated that green tea had no beneficial effect on BP, but another one [39] reported beneficial effects from green tea on "blood-vessel vasodilation". Recently, a systematic review using blinded-only clinical trials to assess the evidence for the efficacy of the green tea extracts on BP concluded that these may cause significant reductions in SBP and recommend long-term independent clinical trials [40].

It should be mentioned that sometimes the cross-cultural approach is successful to discover the potentially useful effects of plants in the management of hypertension. For example, the effects of cocoa (a complex mixture of polyphenols) were detected observing a different prevalence of hypertension after drastic dietary changes. Some Kuna Indians living on San Blas Island (Panama), who consistent had a healthy low blood pressure unaffected by age, migrated to the mainland and consumed up to 10 times less cocoa. In this subpopulation, the prevalence of hypertension increased, and the age-dependent rise of blood pressure appeared in a short period of time [41]. Cocoa, a product derived from the beans of the Theobroma cacao tree, is a potential source of bioactive compounds, but the commercial products may add undesirable calories, sugars, and fats to the diet. However, the European Food Safety Authority recently issued a positive scientific statement on cocoa flavanols, indicating a possible role in the maintenance of "normal endothelium-dependent vasodilation" [42]. We have recently characterized the composition in polyphenols of a novel T. cacao extract, and we found a high antioxidant activity of flavonoids and their metabolites in vitro, which depends on the arrangement of functional groups around the nuclear structure and the substitution pattern of the hydroxyl groups [43]. The use of extracts avoids the ingestion of non-desired nutrients, but has not been proved clinically. Cocoa, however, has been associated with a modest but statistically significant effect on lowering SBP and DBP (of 2.8-3.7 $\mathrm{mmHg}$ and 2.2$2.7 \mathrm{mmHg}$, respectively). None of the studies measured health outcomes $[44,45]$.

Different mixtures of polyphenols provide beneficial effects in the management of hypertension. Whether mixing extracts from different plants may result in a safe and correct approach remains to be established. Data in the literature are difficult to compare but apparently confirm that the use of high doses of polyphenols is essential to obtain significant reductions in BP. We recognize that the differences in the phytochemical composition limit comparisons between extracts in assessing the effects on BP. For example, we obtain substantially higher effects with elevated doses of HS extract in patients with metabolic syndrome (a change in 24-h SBP of $-11.0 \pm 6.3 \mathrm{mmHg}$; $\mathrm{p}<0.001$ vs. baseline) and 24-h DBP $(-4.2 \pm 1.9 \mathrm{mmHg} ; \mathrm{p}<0.001 \mathrm{vs}$. baseline $)$. Of note, reductions only occurred during the daytime, and the heart rate was significantly $(\mathrm{p}=0.012)$ decreased after the intervention period $(70.5 \pm 11.5$ beats $/ \mathrm{min})$ with respect to the baseline value (76.3 \pm 11.8 beats $/ \mathrm{min})$ [9].

\section{Polyphenols and Hypertension: Teas, Extracts, or Isolated Compounds? $\nabla$}

Because dose is important for the size of the effect, herbal teas cannot provide the necessary amounts of polyphenols unless the consumption is continuous during the day. In contrast to HS extracts or related beverages, some herbal teas or other sources of polyphenols may depict side effects (i.e., excitatory effect, increase in caloric intake, etc.). Therefore, our recommendation of high doses, which requires preparation and the release of extracts, significantly increases the cost of fabrication, especially when polyphenols are further isolated to manufacture capsules (see Supporting Information) [46-52]. Additionally, polyphenols exist as complex mixtures of related compounds in foods. The amino acid phenylalanine, in which one or more hydroxyl groups are introduced into the phenyl ring, producing phenols, is the first building block to produce thousands of different structures by adding acetate and sugars. It remains unknown whether this complexity is relevant for our diet [47]; synergism among polyphenols cannot be discarded [48]. The phytochemical composition of foods reveals a high variety of polyphenols ( $>500)$ in common plant foods (http://www.phenol-explorer.eu), and the possibility of finding structure-activity relations is unlikely. On the other hand, the study individual polyphenols is not frequent (e.g., resveratrol, quercetin, epigallocatechin-3-gallate, naringenin, curcumin), but substantial efforts have been made under 
false assumptions implicating that complexity decreases when polyphenols are isolated. Besides, the likelihood of toxic effects is higher than the administration of equivalent amounts as natural mixtures. Indeed, most marketed drugs for single actions synchronously modulate dozens of proteins and receptors. We have already documented this phenomenon with simple drugs such as glitazones or fibrates using the combination of metabolomics and transcriptomics with a focus on obtaining changes in the metabolic status (i.e., the so-called modern Systems Biology) [53]. Moreover, the assessment of the predictive value of the effects of isolated compounds using common in vitro models should be cautious, and extrapolations to in vivo models are useless, especially when explorations are performed with non-metabolized polyphenols and nonphysiological, usually high, doses.

The theoretical basis to explain the effect of polyphenols remains unclear, but it appears now well established that polyphenols seem to have evolved to adapt to different metabolic structures, suggesting an inherent potential to exert multiple pharmacological effects [54]. Taken together, our results and those reviewed in the literature suggest that a multifaceted and likely synergistic mechanism accounts for the hypotensive action of polyphenolrich HS, which acts through different molecular targets specifically directed to improve endothelium-dependent vasodilation. Inflammation, endothelial dysfunction, and oxidation are apparently interrelated mechanisms that play a substantial role in the pathogenesis of hypertension [55]. Effects on diuresis should be added to these mechanisms [56]. We have also found that the HS extract strongly inhibits xanthine oxidase, a superoxide-producing enzyme, and 15-lipoxygenase, which may control the formation of eicosanoids in inflammatory cells [9]. Polyphenols also decrease the circulating levels of inflammatory cytokines regulating the migration of immune cells to tissues, and it is likely that these actions could improve cardiovascular health $[48,49]$. The inflammation inhibition of polyphenols is mostly observed at the transcription level in ex vivo models with a reduced production (and likely activation and translocation) of NF- $k$ B, a major transcription peptide involved in the expression of inflammatory mediators [9].

Chemically, all polyphenols are antioxidant (in vitro). According to the antioxidant hypothesis, the oxidant by-products of normal metabolism cause extensive damage to biomolecules, which is associated with diseases of aging, such as cardiovascular disease. Consequently, the antioxidant defenses are important against this damage, and it is plausible that a supplemental intake of antioxidants would protect against diseases [57-59]. In this scenario, polyphenols show a common and potent antioxidant activity in vitro, but the possible effect in vivo is debatable and does not necessarily represent a common biological action. The absence of significant changes in the antioxidant capacity of plasma after the ingestion of considerable amounts of polyphenols is unsatisfactory $[59,60]$. The detection of effects in the markers of lipid peroxidation and natural antioxidant enzymes are either low or negligible. Whether the effects of polyphenols are relevant in oxidative stress remains to be ascertained, but it is most unlikely as a result of their poor absorption and rapid metabolism and elimination. Additionally, polyphenols represent $<1-2 \%$ of the plasma antioxidants, which include proteins, ascorbate, tocopherol, carotenoids, bilirubin, uric acid, and several other compounds [60,61]. More importantly, the antioxidant activity is obviously welcome, but it is not necessary to explain the effects on BP. Effects on enzymes, cell-signaling pathways, and effects in gene expression may readily explain the beneficial effects on en- dothelial function, metabolic disturbances, and vascular inflammation [62-65]. Intriguingly, although less explored, it has been recently suggested that polyphenols may be important on mitochondrial processes relevant to hypertension, such as membrane potential maintenance and cell survival [66]. Finally, the HS extract decreases the activity of the renin-angiotensin system (RAS) in animal models and in patients with metabolic syndrome and hypertension $[9,67]$. This effect was further sustained by the finding of elevated serum concentrations of a vasodilator, des-Arg (9)-bradykinin, which strongly suggests the action of the HS extract as a potent inhibitor in vivo of the angiotensin converting enzyme (unpublished data). The interrelated effects resulting in a decrease of RAS activity may help to understand the beneficial actions of polyphenols and/or associated compounds. Hypertension, diabetes, obesity, and cortisol stimulate RAS activity, and an activated RAS is closely related to the metabolic syndrome [68]. Conversely, the inhibition of RAS activity improves the mentioned derangements [69].

\section{Perspectives and Implications \\ $\nabla$}

Hypertension prevalence is on the rise. Despite advances in hypertension treatment, only about one-third of all patients with hypertension are controlled in Western societies. We present evidence that polyphenols (at least those from HS, green tea, and cocoa) could be important additions to improve the management of hypertension. Epidemiological data also suggest that a regular consumption of phytochemicals is associated with a reduced risk of developing cardiovascular diseases [70]. However, these findings are difficult to verify without further financial effort. Wellconducted, adequately powered clinical trials with a long duration of intervention and a standardized composition in polyphenols to evaluate their effects on BP and other metabolic derangements are warranted. This is expensive, and reluctance is a common feeling in industries dealing with hypertension.

We acknowledge that it is of great significance to elucidate the therapeutic mechanisms of polyphenols. This is a considerable challenge because polyphenols hit multiple targets with relatively weak affinity, and multiple polyphenols may represent an increase in the number of effects. To clarify these mechanisms, the metabolism of polyphenols should be incorporated into future approaches. Complexity is an inherent characteristic in the assessment of both pharmacological and dietary interventions, as the concentration of many metabolites may change in a scenario in which thousands of reactions continuously transform metabolites into each other. Ongoing studies will probably refine and confirm this approach as a promising tool for capturing metabolic complexity caused by plant-derived extracts. We expect that the interpretation of the induced metabolic changes using this technology and potent bioinformatics tools [71] will result in the knowledge of the effects on hypertension caused by specific polyphenol metabolites. Indeed, recent efforts reinforce this approach [72] recognizing the fact that we generally have incomplete knowledge of the molecular pathways by which drugs act [73]. The current relationship between polyphenols and hypertension is questionable and disappointing in some aspects. It is acknowledged that the undertreatment of hypertension is a serious medical problem and that plant-derived polyphenols, as a complementary approach, may be potentially helpful. Substantial knowledge to ascertain the benefit in the population has been 
developed, and it is available, but existing efforts are troubled by financial or patent-related difficulty.

\section{Supporting information}

The methods used to obtain and characterize HS aqueous extracts and the corresponding purified extracts are available as Supporting Information.

\section{Acknowledgements}

$\nabla$

This study was supported by grants from the Carlos III Health Institute, Madrid, Spain (PI08/1381, PI11/00130), and the European Fund for Regional Development. Research materials related to this manuscript are available on request from the corresponding author.

\section{Conflict of Interest}

All authors contributed to and have approved the final manuscript. We declare not to have any conflict of interest regarding the publication of this manuscript.

\section{References}

1 James PA, Oparil S, Carter BL, Cushman WC, Dennison-Himmelfarb C, Handler J, Lackland DT, LeFevre ML, MacKenzie TD, Ogedegbe O, Smith SC jr., Svetkey LP, Taler SJ, Townsend RR, Wright JT jr., Narva AS, Ortiz E. 2014 evidence-based guideline for the management of high blood pressure in adults: report from the panel members appointed to the Eighth Joint National Committee (JNC 8). JAMA 2014; 311: 507-520

2 Rodriguez CJ, Swett K, Agarwal SK, Folsom AR, Fox ER, Loehr LR, Ni H, Rosamond WD, Chang PP. Systolic blood pressure levels among adults with hypertension and incident cardiovascular events: the atherosclerosis risk in communities study. JAMA Intern Med 2014; 174: 1252-1261

3 Ferré N, Feliu A, García-Heredia A, Marsillach J, París N, Zaragoza-Jordana M, Mackness B, Mackness M, Escribano J, Closa-Monasterolo R, Joven J, Camps J. Impaired paraoxonase-1 status in obese children. Relationships with insulin resistance and metabolic syndrome. Clin Biochem 2013; 46: 1830-1836

4 Calhoun DA, Jones D, Textor S, Goff DC, Murphy TP, Toto RD, White A, Cushman WC, White W, Sica D, Ferdinand K, Giles TD, Falkner B, Carey $R M$. Resistant hypertension: diagnosis, evaluation, and treatment. A scientific statement from the American Heart Association Professional Education Committee of the Council for High Blood Pressure Research. Hypertension 2008; 51: 1403-1419

5 Black HR, Elliott WJ, Neaton JD, Grandits G, Grambsch P, Grimm RH jr., Hansson L, Lacouciere Y, Muller J, Sleight P, Weber MA, White WB, Williams G, Wittes J, Zanchetti A, Fakouhi TD, Anders RJ. Baseline characteristics and early blood pressure control in the CONVINCE trial. Hypertension 2001; 37: 12-18

6 Burt VL, Cutler JA, Higgins M, Horan MJ, Labarthe D, Whelton P, Brown C, Roccella EJ. Trends in the prevalence, awareness, treatment, and control of hypertension in the adult US population. Data from the health examination surveys, 1960-1991. Hypertension 1995; 26: 60-69

7 Phillips LS, Branch WT, Cook CB, Doyle JP, El-Kebbi IM, Gallina DL, Miller CD, Ziemer DC, Barnes CS. Clinical inertia. Ann Intern Med 2001; 135 : 825-834

8 I've heard the hibiscus tea is helpful for high blood pressure. Is that true? Mayo Clin Health Lett 2014; 32: 8

9 Joven J, March I, Espinel E, Fernández-Arroyo S, Rodríguez-Gallego E, Aragonès G, Beltrán-Debón R, Alonso-Villaverde C, Rios L, Martin-Paredero $V$, Menendez JA, Micol V, Segura-Carretero A, Camps J. Hibiscus sabdariffa extract lowers blood pressure and improves endothelial function. Mol Nutr Food Res 2014; 58: 1374-1378

10 Ali BH, Al Wabel N, Blunden G. Phytochemical, pharmacological, and toxicological aspects of Hibiscus sabdariffa L.: a review. Phytother Res 2005; 19: 369-375

11 Tseng TH, Kao ES, Chu CY, Chou FP, Lin Wu HW, Wang CJ. Protective effects of dried flower extracts of Hibiscus sabdariffa L. against oxidative stress in rat primary hepatocytes. Food Chem Toxicol 1997; 35: 11591164

12 Aguwa CN, Ndu OO, Nwanma CC, Udeogaranya PO, Akwara NO. Verification of the folkloric diuretic claim of Hibiscus sabdariffa L. petal extract. Nigerian J Pharm Res 2004; 3: 1-8

13 Alarcon-Aguilar FJ, Zamilpa A, Perez-Garcia MD, Almanza-Perez JC, Romero-Nuñez E, Campos-Sepulveda EA, Vazquez-Carrillo LI, Roman-Ramos $R$. Effect of Hibiscus sabdariffa on obesity in MSG mice. J Ethnopharmacol 2007; 114: 66-71

14 Cáceres A, Girón LM, Martínez AM. Diuretic activity of plants used for the treatment of urinary ailments in Guatemala. J Ethnopharmacol 1987; 19: 233-245

15 Onyenekwe PC, Ajani EO, Ameh DA, Gamaniel KS. Antihypertensive effect of roselle (Hibiscus sabdariffa) calyx infusion in spontaneously hypertensive rats and a comparison of its toxicity with that in Wistar rats. Cell Biochem Funct 1999; 17: 199-206

16 Ribeiro Rde A, de Barros F, de Melo MM, Muniz C, Chieia S, Wanderley M das G, Gomes C, Trolin G. Acute diuretic effects in conscious rats produced by some medicinal plants used in the state of São Paulo, Brasil. J Ethnopharmacol 1988; 24: 19-29

17 Herrera-Arellano A, Miranda-Sánchez J, Avila-Castro P, Herrera-Alvarez $S$, Jiménez-Ferrer JE, Zamilpa A, Román-Ramos R, Ponce-Monter H, Tortoriello $\mathrm{J}$. Clinical effects produced by a standardized herbal medicinal product of Hibiscus sabdariffa on patients with hypertension. A randomized, double-blind, lisinopril-controlled clinical trial. Planta Med 2007; 73: 6-12

18 Kirdpon S, Nakorn SN, Kirdpon W. Changes in urinary chemical composition in healthy volunteers after consuming roselle (Hibiscus sabdariffa Linn.) juice. J Med Assoc Thai 1994; 77: 314-321

19 Prasongwatana V, Woottisin S, Sriboonlue P, Kukongviriyapan V. Uricosuric effect of Roselle (Hibiscus sabdariffa) in normal and renal-stone former subjects. J Ethnopharmacol 2008; 117: 491-495

20 Wahabi HA, Alansary LA, Al-Sabban AH, Glasziuo P. The effectiveness of Hibiscus sabdariffa in the treatment of hypertension: a systematic review. Phytomedicine 2010; 17: 83-86

21 Ngamjarus C, Pattanittum P, Somboonporn C. Roselle for hypertension in adults. Cochrane Database Syst Rev 2010: CD007894

22 Mancia G, Omboni S, Parati G, Ravogli A, Villani A, Zanchetti A. Lack of placebo effect on ambulatory blood pressure. Am J Hypertens 1995; 8: 311-315

23 Nissen N, Manderson L. Researching alternative and complementary therapies: mapping the field. Med Anthropol 2013; 32: 1-7

24 Fønnebø V, Grimsgaard S, Walach H, Ritenbaugh C, Norheim AJ, MacPherson H, Lewith G, Launsø L, Koithan M, Falkenberg T, Boon H, Aickin $M$. Researching complementary and alternative treatments-the gatekeepers are not at home. BMC Med Res Methodol 2007; 7: 7

25 Hopkins AL, Lamm MG, Funk JL, Ritenbaugh C. Hibiscus sabdariffa L. in the treatment of hypertension and hyperlipidemia: a comprehensive review of animal and human studies. Fitoterapia 2013; 85: 84-94

26 Mohagheghi A, Maghsoud S, Khashayar P, Ghazi-Khansari M. The effect of Hibiscus sabdariffa on lipid profile, creatinine, and serum electrolytes: a randomized clinical trial. ISRN Gastroenterol 2011; 2011: 976019 DOI: $10.5402 / 2011 / 976019$

27 McKay DL, Chen CYO, Saltzman E, Blumberg JB. Hibiscus sabdariffa L. tea (tisane) lowers blood pressure in prehypertensive and mildly hypertensive adults. J Nutr 2010; 140: 298-303

28 Gurrola-Diaz CM, Garcia-Lopez PM, Sanchez-Enriquez S, Troyo-Sanroman R, Andrade-Gonzalez I, Gomez-Leyva JF. Effects of Hibiscus sabdariffa extract powder and preventive treatment (diet) on the lipid profiles of patients with metabolic syndrome (MeSy). Phytomedicine 2010; 17: 500-505

29 Ali BH, Wabel NA, Blunden G. Phytochemical, pharmacological and toxicological aspects of Hibiscus sabdariffa L.: a review. Phytother Res 2005; 19: 369-375

30 Haji Faraji M, Haji Tarkhani AH. The effect of sour tea (Hibiscus sabdariffa) on essential hypertension. J Ethnopharmacol 1999; 65: 231-236

31 Mozaffari-Khosravi H, Jalali-Khanabadi BA, Afkhami-Ardekani M, Fatehi $F$, Noori-Shadkam M. The effects of sour tea (Hibiscus sabdariffa) on hypertension in patients with type II diabetes. J Hum Hypertens 2009; 23: $48-54$

32 Holmes JS, Shevrin M, Goldman B, Share D. Translating research into practice: are physicians following evidence-based guidelines in the treatment of hypertension? Med Care Res Rev 2004; 61: 453-473 
33 Cranney $M$, Warren E, Walley T. Hypertension in the elderly: attitudes of British patients and general practitioners. J Hum Hypertens 1998; 12: 539-545

34 Sever P, Beevers G, Bulpitt CJ. Management guidelines in essential hypertension: report of the second working party of the British Hypertension Society. BMJ 1993; 306: 983-987

35 Cranney M, Warren E, Barton W, Gardner K, Walley T. Why do GPs not implement evidence-based guidelines? A descriptive study. Fam Pract 2001; 18: 359-363

36 Cheng TO. All teas are not created equal: the Chinese green tea and cardiovascular health. Int J Cardiol 2006; 108: 301-308

37 Steen RG, Dager SR. Evaluating the evidence for evidence-based medicine: are randomized clinical trials less flawed than other forms of peer-reviewed medical research? FASEB J 2013; 27: 3430-3436

38 Taubert D, Roesen $R$, Schömig E. Effect of cocoa and tea intake on blood pressure: a meta-analysis. Arch Intern Med 2007; 167: 626-634

39 Ras RT, Zock PL, Draijer $R$. Tea consumption enhances endothelial-dependent vasodilation; a meta-analysis. PLoS One 2011; 6: e16974

40 Onakpoya I, Spencer E, Heneghan C, Thompson $M$. The effect of green tea on blood pressure and lipid profile: a systematic review and metaanalysis of randomized clinical trials. Nutr Metab Cardiovasc Dis 2014; 24: 823-836

41 Ried K, Sullivan TR, Fakler P, Frank OR, Stocks NP. Effect of cocoa on blood pressure. Cochrane Database Syst Rev 2012; 8: CD008893

42 European Food Safety Authority (EFSA) Panel on Dietetic Products, Nutrition and Allergies. Scientific opinion on the substantiation of a health claim related to cocoa flavanols and maintenance of normal endothelium-dependent vasodilation pursuant to Article 13(5) of Regulation (EC) No. 1924/20061. EFSA J 2012; 10: 2809

43 Cádiz-Gurrea ML, Lozano-Sanchez J, Contreras-Gámez M, Legeai-Mallet L, Fernández-Arroyo S, Segura-Carretero A. Isolation, comprehensive characterization and antioxidant activities of Theobroma cacao extract. J Funct Foods 2014; 10: 485-498

$44 \mathrm{Gu}$ Y, Lambert JD. Modulation of metabolic syndrome-related inflammation by cocoa. Mol Nutr Food Res 2013; 57: 948-961

45 Kim J, Kim J, Shim J, Lee CY, Lee KW, Lee HJ. Cocoa phytochemicals: recent advances in molecular mechanisms on health. Crit Rev Food Sci Nutr 2014; 54: 1458-1472

46 Fernández-Arroyo S, Herranz-López M, Beltrán-Debón R, Borrás-Linares I, Barrajón-Catalán E, Joven J, Fernández-Gutiérrez A, Segura-Carretero A, Micol V. Bioavailability study of a polyphenol-enriched extract from Hibiscus sabdariffa in rats and associated antioxidant status. Mol Nutr Food Res 2012; 56: 1590-1595

47 Joven J, Espinel E, Rull A, Aragonès G, Rodríguez-Gallego E, Camps J, Micol $V$, Herranz-López M, Menéndez JA, Borrás I, Segura-Carretero A, AlonsoVillaverde C, Beltrán-Debón R. Plant-derived polyphenols regulate expression of miRNA paralogs miR-103/107 and miR-122 and prevent diet-induced fatty liver disease in hyperlipidemic mice. Biochim Biophys Acta 2012; 1820: 894-899

48 Herranz-López M, Fernández-Arroyo S, Pérez-Sanchez A, Barrajón-Catalán E, Beltrán-Debón R, Menéndez JA, Alonso-Villaverde C, Segura-Carretero A, Joven J, Micol V. Synergism of plant-derived polyphenols in adipogenesis: perspectives and implications. Phytomedicine 2012; 19 : 253-261

49 Beltrán-Debón R, Alonso-Villaverde C, Aragonès G, Rodríguez-Medina I, Rull A, Micol V, Segura-Carretero A, Fernández-Gutiérrez A, Camps J, Joven $J$. The aqueous extract of Hibiscus sabdariffa calices modulates the production of monocyte chemoattractant protein-1 in humans. Phytomedicine 2010; 17: 186-191

50 Rodríguez-Medina IC, Beltrán-Debón R, Molina VM, Alonso-Villaverde C, Joven J, Menéndez JA, Segura-Carretero A, Fernández-Gutiérrez A. Direct characterization of aqueous extract of Hibiscus sabdariffa using HPLC with diode array detection coupled to ESI and ion trap MS. J Sep Sci 2009; 32: 3441-3448

51 Segura-Carretero A, Puertas-Mejía MA, Cortacero-Ramírez S, Beltrán R, Alonso-Villaverde C, Joven J, Dinelli G, Fernández-Gutiérrez A. Selective extraction, separation, and identification of anthocyanins from Hibiscus sabdariffa L. using solid phase extraction-capillary electrophoresis-mass spectrometry (time-of-flight/ion trap). Electrophoresis 2008; 29: 2852-2861

52 Masana L, Camprubi M, Sarda P, Sola R, Joven J, Turner PR. The Mediterranean-type diet: is there a need for further modification? Am J Clin Nutr 1991; 53: 886-889

53 Rull A, Geeraert B, Aragonès G, Beltrán-Debón R, Rodríguez-Gallego E, García-Heredia A, Pedro-Botet J, Joven J, Holvoet P, Camps J. Rosiglita- zone and fenofibrate exacerbate liver steatosis in a mouse model of obesity and hyperlipidemia. A transcriptomic and metabolomic study. J Proteome Res 2014; 13: 1731-1743

54 Ji HF, Li XJ, Zhang HY. Natural products and drug discovery. Can thousands of years of ancient medical knowledge lead us to new and powerful drug combinations in the fight against cancer and dementia? EMBO Rep 2009; 10: 194-200

55 Nijveldt RJ, van Nood E, van Hoorn DEC, Boelens PG, van Norren $K$, van Leeuwen PAM. Flavonoids: a review of probable mechanisms of action and potential applications. Am J Clin Nutr 2001; 74: 418-425

56 Jiménez-Ferrer E, Alarcón-Alonso J, Aguilar-Rojas A, Zamilpa A, JiménezFerrer C I, Tortoriello J, Herrera-Ruiz M. Diuretic effect of compounds from Hibiscus sabdariffa by modulation of the aldosterone activity. Planta Med 2012; 78: 1893-1898

57 Ames BN, Shigenaga MK, Hagen TM. Oxidants, antioxidants, and the degenerative diseases of aging. Proc Natl Acad Sci U S A 1993; 90: 79157922

58 Camps J, Rodríguez-Gallego E, García-Heredia A, Triguero I, Riera-Borrull M, Hernández-Aguilera A, Luciano-Mateo F, Fernández-Arroyo S, Joven J. Paraoxonases and chemokine ( $\mathrm{C}-\mathrm{C}$ motif) ligand-2 in noncommunicable diseases. Adv Clin Chem 2014; 63: 247-308

59 Rull A, Camps J, Alonso-Villaverde C, Joven J. Insulin resistance, inflammation, and obesity: role of monocyte chemoattractant protein-1 (or CCL2) in the regulation of metabolism. Mediators Inflamm 2010; 2010: 326580

60 Hollman PC, Cassidy A, Comte B, Heinonen M, Richelle M, Richling E, Serafini $M$, Scalbert $A$, Sies $H$, Vidry $S$. The biological relevance of direct antioxidant effects of polyphenols for cardiovascular health in humans is not established. J Nutr 2011; 141: 989S-1009S

61 Qian G, Xue K, Tang L, Wang F, Song X, Chyu MC, Pence BC, Shen CL, Wang $J S$. Mitigation of oxidative damage by green tea polyphenols and Tai Chi exercise in postmenopausal women with osteopenia. PLoS One 2012 7: e48090

62 Joven J, Micol V, Segura-Carretero A, Alonso-Villaverde C, Menéndez JA. Polyphenols and the modulation of gene expression pathways: can we eat our way out of the danger of chronic disease? Crit Rev Food Sci Nutr 2014; 54: 985-1001

63 Rull A, Rodríguez F, Aragonès G, Marsillach J, Beltrán R, Alonso-Villaverde C, Camps J, Joven J. Hepatic monocyte chemoattractant protein-1 is upregulated by dietary cholesterol and contributes to liver steatosis. $\mathrm{Cy}$ tokine 2009; 48: 273-279

64 Tous M, Ferré N, Rull A, Marsillach J, Coll B, Alonso-Villaverde C, Camps J, Joven $J$. Dietary cholesterol and differential monocyte chemoattractant protein-1 gene expression in aorta and liver of apo E-deficient mice. Biochem Biophys Res Commun 2006; 340: 1078-1084

65 Marsillach J, Camps J, Ferré N, Beltran R, Rull A, Mackness B, Mackness M, Joven J. Paraoxonase- 1 is related to inflammation, fibrosis and PPAR delta in experimental liver disease. BMC Gastroenterol 2009; 9: 3

66 Duluc L, Jacques C, Soleti R, Iacobazzi F, Simard G, Andriantsitohaina $R$. Modulation of mitochondrial capacity and angiogenesis by red wine polyphenols via estrogen receptor, NADPH oxidase and nitric oxide synthase pathways. Int J Biochem Cell Biol 2013; 45: 783-791

67 Ojeda D, Jiménez-Ferrer E, Zamilpa A, Herrera-Arellano A, Tortoriello J, Alvarez $L$. Inhibition of angiotensin converting enzyme (ACE) activity by the anthocyanins delphinidin- and cyanidin-3-O-sambubiosides from Hibiscus sabdariffa. J Ethnopharmacol 2010; 127: 7-10

68 Kalupahana NS, Moustaid-Moussa N. The renin-angiotensin system: a link between obesity, inflammation and insulin resistance. Obes Rev 2012; 13: 136-149

69 Vaidya A, Williams JS. The relationship between vitamin D and the renin-angiotensin system in the pathophysiology of hypertension, kidney disease, and diabetes. Metabolism 2012; 61: 450-458

$70 \mathrm{Hu}$ FB. Plant-based foods and prevention of cardiovascular disease: an overview. Am J Clin Nutr 2003; 78 (Suppl. 3): S544-S551

71 Manach C, Hubert J, Llorach R, Scalbert A. The complex links between dietary phytochemicals and human health deciphered by metabolomics. Mol Nutr Food Res 2009; 53: 1303-1315

72 Gottlieb A, Altman RB. Integrating systems biology sources illuminates drug action. Clin Pharmacol Ther 2014; 95: 663-669

73 Joven J, Rull A, Rodriguez-Gallego E, Camps J, Riera-Borrull M, Hernández-Aguilera A, Martin-Paredero V, Segura-Carretero A, Micol V, Alonso-Villaverde $C$, Menéndez JA. Multifunctional targets of dietary polyphenols in disease: a case for the chemokine network and energy metabolism. Food Chem Toxicol 2013; 51: 267-279 